\title{
Typhoid Fever due to Extended Spectrum $\beta$-Lactamase-Producing Salmonella enterica Serovar Typhi: A Case Report and Literature Review
}

\author{
Abdul Azeez Ahamed Riyaaz $\mathbb{D}^{D},{ }^{1}$ Vindya Perera $\mathbb{D}^{\mathrm{D}},{ }^{2}$ Sabaratnam Sivakumaran, ${ }^{1}$ and \\ Nelun de Silva ${ }^{2}$ \\ ${ }^{1}$ Department of Internal Medicine, Dr. Neville Fernando Teaching Hospital, Malabe, Sri Lanka \\ ${ }^{2}$ Department of Microbiology, Faculty of Medicine, South Asian Institute of Technology and Medicine, Malabe, Sri Lanka \\ Correspondence should be addressed to Vindya Perera; v.perera83@yahoo.com
}

Received 14 September 2017; Revised 25 December 2017; Accepted 14 January 2018; Published 15 February 2018

Academic Editor: Larry M. Bush

Copyright (c) 2018 Abdul Azeez Ahamed Riyaaz et al. This is an open access article distributed under the Creative Commons Attribution License, which permits unrestricted use, distribution, and reproduction in any medium, provided the original work is properly cited.

\begin{abstract}
Emergence of cephalosporin-resistant strains of Salmonella enterica serovar Typhi is a cause of concern in the management of enteric fever. Cephalosporin resistance in Salmonella species is mainly due to the production of extended-spectrum $\beta$-lactamases (ESBLs). The majority of ESBLs in Salmonella enterica serovar Typhi are derivatives of the TEM, SHV, and CTX-M $\beta$-lactamase families. Of these, CTX-M appears to be predominant. This paper discusses the detection and molecular characterization of an ESBL-producing Salmonella enterica serovar Typhi strain isolated from a patient who was admitted to a private hospital in Sri Lanka. The three main types of $\beta$-lactamases such as TEM, SHV, and CTX-M were identified in this isolate. This case report from Sri Lanka contributes to the knowledge of the increasingly reported cases of typhoid fever due to Salmonella enterica serovar Typhi resistant to $\beta$-lactamase by ESBL production.
\end{abstract}

\section{Introduction}

The emergence of resistance to fluoroquinolones had led to the frequent use of azithromycin for empirical treatment of uncomplicated enteric fever and the use of third-generation cephalosporins as the first-line drug for intravenous treatments [1]. However, the recent emergence of cephalosporinresistant strains of Salmonella enterica serovar Typhi is a cause for concern in the management of enteric fever. Cephalosporin resistance in Salmonella species is mainly due to the production of extended-spectrum $\beta$-lactamases (ESBLs). The majority of ESBLs in Salmonella are derivatives of the TEM, SHV, and CTX-M $\beta$-lactamase families.

The production of ESBL leads to multidrug resistance in Salmonella enterica isolates. Multidrug resistance (MDR) in Salmonella enterica has been described around the world and shown to be more common in Salmonella Typhi than in Salmonella Paratyphi $[2,3]$. The geographic variations have been described for MDR Salmonella Typhi isolates in Asia. For example, some studies have shown higher prevalence of MDR phenotypes in India, Pakistan, and Vietnam when compared to those in China and Indonesia [4]. In developed countries such as the United States and Germany, Salmonella Typhi with MDR has been reported with travel to developing countries $[5,6]$.

In Sri Lanka, there are no published data on molecular characteristics of ESBL-producing Salmonella enterica serovar Typhi. This case reports the detection and molecular characterization of an ESBL-producing Salmonella enterica serovar Typhi strain isolated from a patient with typhoid fever who was admitted to a private hospital in Sri Lanka.

\section{Case Presentation}

An 18-year-old previously healthy male was admitted to our medical unit with a history of fever of 5-day duration. He had high-grade fever associated with generalized aches and 
frontal headache. He denied any respiratory or urinary symptoms. He mentioned that he had not passed faeces for the last three days but had developed nonbloody diarrhoea on the day of admission without any vomiting or abdominal pain. He denied any recent travel, but he had been eating from various food outlets for the past 2 weeks during his after-school cricket practice sessions.

On examination, he was not ill looking despite his temperature of $40^{\circ} \mathrm{C}$. There were no pallor, icterus, lymphadenopathy, and skin rashes. Cardiovascular and respiratory examination was normal. Abdominal examination revealed a soft, nontender abdomen with a $3 \mathrm{~cm}$ nontender hepatomegaly and a $2 \mathrm{~cm}$ splenomegaly. His blood test showed a haemoglobin count of $14.8 \mathrm{~g} / \mathrm{dl}$, a white cell count of $2.8 \times 10^{9} / 1$ (neutrophils $79 \%$ and lymphocytes $14 \%$ ), and a platelet count of $97 \times 10^{9} /$ l. Dengue NS1 antigen and IgM against dengue virus detected by a commercial kit (Standard Diagnostics, Inc., Germany) were negative. C-reactive protein (CRP) was elevated more than $250 \mathrm{mg} / \mathrm{dl}$ in two subsequent samples. His liver function tests were normal except elevated liver transaminases (ALT $145 \mathrm{U} / \mathrm{l}$ and AST $118 \mathrm{U} / \mathrm{l}$; ALT/ASTnormal range 8-40 U/L). An ultrasound scan of the abdomen confirmed mild hepatosplenomegaly. On days 2 and 3 of his admission, he continued to have high fever spikes, diarrhoea, and persistent thrombocytopenia with a high CRP.

Intravenous ceftriaxone $2 \mathrm{~g}$ daily was commenced. After 48 hours, the patients' clinical condition had not improved and the high fever spikes continued. After antibiotic susceptibility test results, his antibiotic was changed to imipenem 1 g 8 hourly. He showed clinical improvement after 48 hours, but the diarrhoea and fever settled only around the 10th day of treatment. Imipenem was continued for a total duration of 14 days. His platelet count, liver transaminases, and CRP returned to normal. A repeat blood and faeces culture performed on discharge was negative for Salmonella enterica serovar Typhi.

\section{Laboratory Methods}

The blood culture from the patient grew nonlactose fermenting colonies on MacConkey agar which were identified as Salmonella enterica serovar Typhi by standard laboratory methods and by the Rapid ID Test Kit (Oxoid).

The antibiotic-susceptibility results of the isolate performed according to CLSI disc diffusion method [2] showed resistance to antibiotics such as ampicillin, chloramphenicol, ciprofloxacin, cotrimoxazole, and co-amoxiclav. The isolate was susceptible to imipenem, meropenem, ertapenem, amikacin, and netilmicin but was resistant to cefotaxime, cefixime, cefepime, and aztreonam (Table 1). The resistance was further confirmed by determining the minimum inhibitory concentrations (MIC in $\mu \mathrm{g} / \mathrm{ml}$ ) of the antibiotics to the isolate by VITEK ${ }^{\circledR} 2$ system, and the results were as follows: ciprofloxacin $>4$, ceftriaxone $>64$, ceftazidime $>64$, imipenem $<0.25$, and ertapenem $<0.5$ (Table 2 ).

ESBL production of the isolate was screened according to CLSI breakpoints for cefpodoxime, ceftazidime, aztreonam, cefotaxime, and ceftriaxone. The combined disc test was done using ceftazidime and cefotaxime individually and in
TABle 1: Antimicrobial susceptibility results of the isolate according to CLSI disc diffusion method.

\begin{tabular}{lc}
\hline Antimicrobial & CLSI disc diffusion method (interpretation) \\
\hline Ampicillin & $\mathrm{R}$ \\
Chloramphenicol & $\mathrm{R}$ \\
Ciprofloxacin & $\mathrm{R}$ \\
Cotrimoxazole & $\mathrm{R}$ \\
Co-amoxiclav & $\mathrm{R}$ \\
Cefotaxime & $\mathrm{R}$ \\
Cefixime & $\mathrm{R}$ \\
Cefepime & $\mathrm{R}$ \\
Aztreonam & $\mathrm{R}$ \\
Imipenem & $\mathrm{S}$ \\
Meropenem & $\mathrm{S}$ \\
Ertapenem & $\mathrm{S}$ \\
Amikacin & $\mathrm{S}$ \\
Netilmicin & $\mathrm{S}$ \\
\hline
\end{tabular}

$\mathrm{R}$, resistance; $\mathrm{S}$, susceptible.

TABle 2: The minimum inhibitory concentrations ( $\mathrm{MIC}$ in $\mu \mathrm{g} / \mathrm{ml}$ ) of the antibiotics to the isolate by VITEK 2 system.

\begin{tabular}{lcc}
\hline Antimicrobial & MIC $(\mathrm{mg} / \mathrm{l})$ & Interpretation \\
\hline Ciprofloxacin & $>4$ & $\mathrm{R}$ \\
Ceftriaxone & $>64$ & $\mathrm{R}$ \\
Ceftazidime & $>64$ & $\mathrm{R}$ \\
Imipenem & $<0.25$ & $\mathrm{~S}$ \\
Ertapenem & $<0.5$ & $\mathrm{~S}$ \\
\hline
\end{tabular}

$\mathrm{R}$, resistance; $\mathrm{S}$, susceptible.

combination with clavulanic acid according to the Clinical and Laboratory Standards Institute (CLSI) guidelines to confirm ESBL production [7]. The isolate was further tested phenotypically with the modified double-disc synergy test (MDDST) by using a disc of amoxicillin-clavulanate along with four cephalosporins: cefotaxime, ceftriaxone, cefpodoxime, and cefepime [8]. Suggestive evidence of ESBL production was observed with reduced susceptibility for the five antimicrobial agents used in CLSI screening test. In the confirmatory test, $>5 \mathrm{~mm}$ increase in zone diameters for the combined discs of ceftazidime and cefotaxime with clavulanic acid versus the zone diameter of the agent when tested alone was observed (Figure 1). In MDDST, a synergy between amoxicillin/clavulanate and four cephalosporins was observed which provided further evidence of ESBL production (Figure 2).

To detect ESBL genes, polymerase chain reaction (PCR) was performed as described previously $[9,10]$. PCR results showed that the isolate harbored $b l a_{\mathrm{TEM}}$ (Figure 3), bla $a_{\mathrm{SHV}}$ (Figure 4), and $b l a_{\text {СтХ-м }}$ (Figure 5) gene types.

\section{Discussion}

Enteric fever is one of the major health concerns in developing countries. Salmonella Typhi enters the lymphatic system after ingestion and then survives and replicates within macrophages, later on disseminating into the reticuloendothelial system. The 


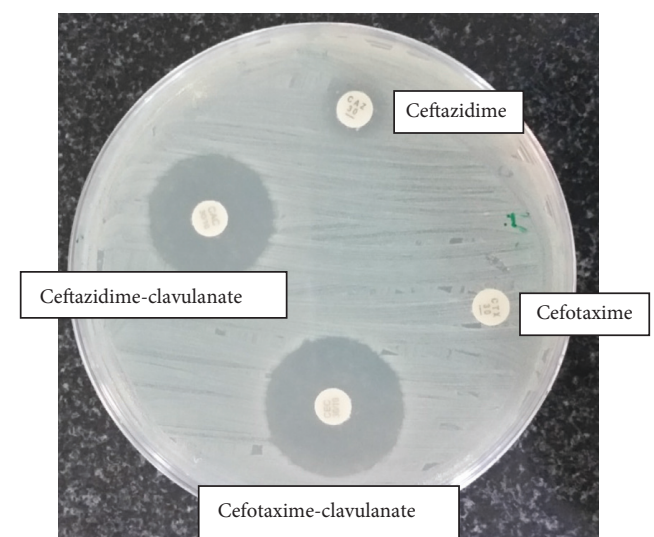

FIGURE 1: CLSI confirmatory test for ESBL production with $>5 \mathrm{~mm}$ increase in zone diameters for combined discs of ceftazidime and cefotaxime with clavulanic acid versus the zone diameter of the agent when tested alone.

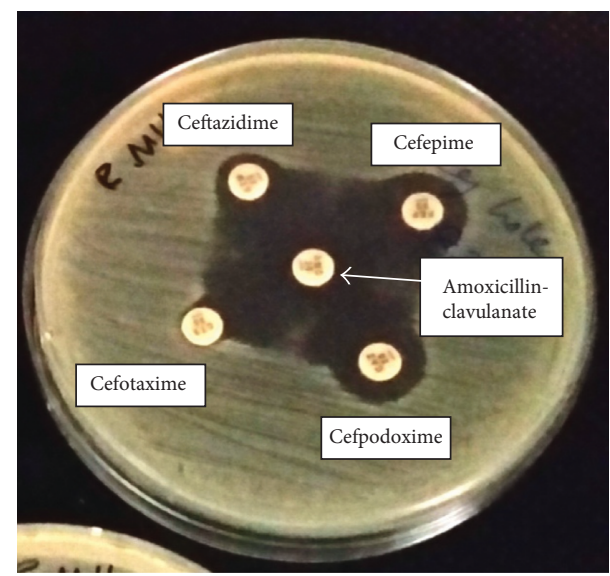

Figure 2: Modified double disc synergy test (MDDST) showing synergy between amoxicillin/clavulanate and four cephalosporins.

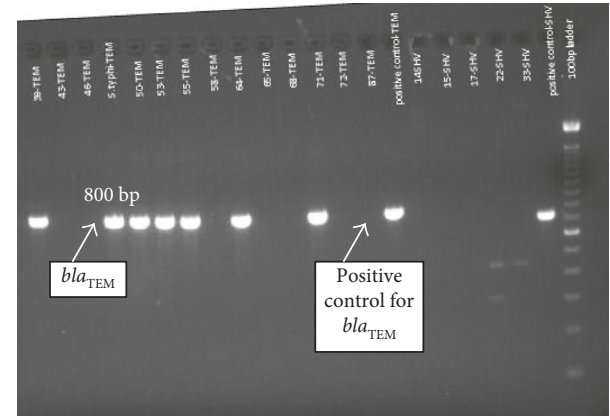

FIGURE 3: Gel image of PCR product showing $b l a_{\mathrm{TEM}}$ gene.

common clinical features of enteric fever include fever, chills, abdominal pain, and appearance of rose spots. Leucopenia and anaemia are well-recognised haematological manifestations of enteric fever. Isolated thrombocytopenia is a rare finding in typhoid fever, and there are only few case reports found in the literature [11]. Our patient had both leucopenia and thrombocytopenia at presentation without anaemia,

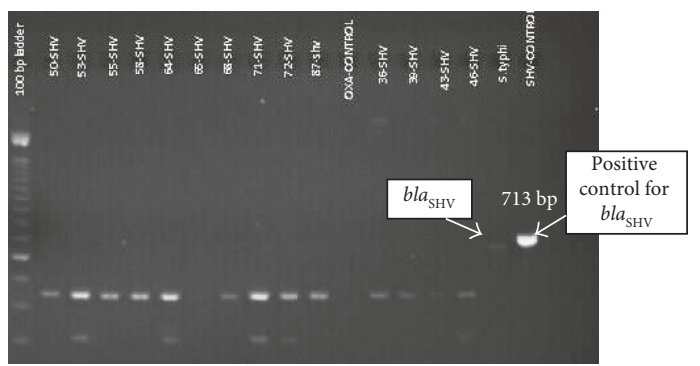

FIgURE 4: Gel image of the PCR product showing $b l a_{\mathrm{SHV}}$ gene.

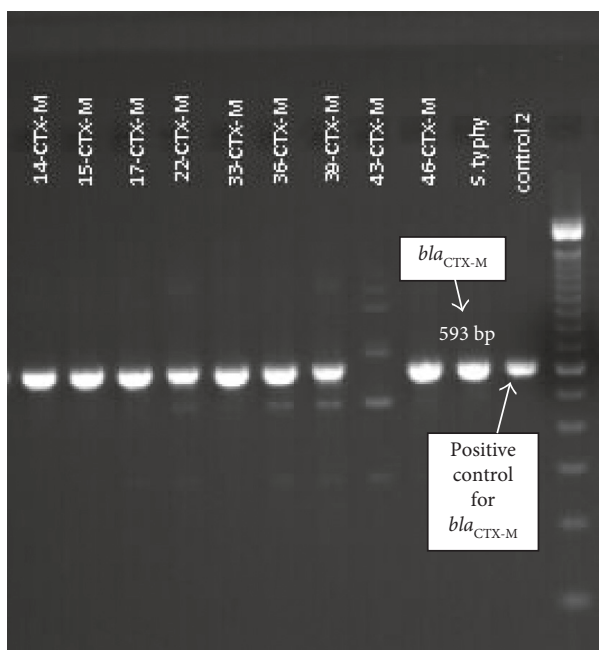

Figure 5: Gel image of the PCR product showing $b l a_{\mathrm{CTX}-\mathrm{M}}$ gene.

which is a common finding in febrile patients due to viral aetiology particularly dengue infection. Our patient presented during a dengue epidemic period where these findings could have been easily overlooked.

According to the literature, multidrug-resistant Salmonella Typhi had been documented more than Salmonella Paratyphi [12-14]. In our study, the isolate was resistant to all first-line antibiotics (i.e., ampicillin, chloramphenicol, cotrimoxazole, and ciprofloxacin).

The production of $\beta$-lactamases is a major factor that makes Gram-negative bacteria resistant to antibiotics [15]. TEM, SHV, and CTX-M are the main types of $\beta$-lactamases produced by these organisms that confer resistance to penicillins and cephalosporins. In this case, we identified the gene types responsible for the production of all the three main types of $\beta$-lactamases.

The TEM-type $\beta$-lactamase is commonly present in Enterobacteriaceae such as Escherichia coli, Klebsiella pneumoniae, and Proteus mirabilis, and SHV types were found to be common in Klebsiella pneumonia [16]. The CTXM-type $\beta$-lactamases were found in E. coli and Klebsiella spp. Salmonella strains were documented to acquire these genes from E. coli and Klebsiella sp. [17]. Variants of these types of $\beta$-lactamases have conferred resistance only to penicillins and early cephalosporins as well as to second-, third-, and fourthgeneration cephalosporins [18].

Several cases of $S$. enterica ser. Typhi resistant to $\beta$-lactamase by ESBL production have been reported in Asian countries. In 
the Philippines, a strain that harbors $b a_{\mathrm{SHV}}$ gene was identified in 2008 [19]. In Kuwait, the United Arab Emirates, and Bangladesh, there had been reports of ESBL-producing Salmonella Typhi with CTX-M genes [20,21]. A study carried out in India in 2013 identified five multidrug-resistant isolates belonging to serotype Salmonella Typhi that were positive to TEM-1-type $\beta$-lactamase, but none of these isolates were positive for SHV- or CTX-M-type $\beta$-lactamase [22]. In the present case, we found a $S$. enterica serovar Typhi positive all TEM-, SHV-, and CTX-M-type $\beta$-lactamases.

The emergence of ESBL-producing Salmonella is a result of selective pressure imposed by the misuse of broadspectrum antibiotics such as third-generation cephalosporins. Increased prevalence of these resistant salmonella will lead to failures of the current treatment practices. Continuous surveillance of the susceptibility profiles and improving infection control measures will help to control the spread of the infection with resistant strains. This case report describes a patient with typhoid fever caused by Salmonella enterica serovar Typhi strain that carried three major genes responsible for the production of ESBL that resulted in resistance to cephalosporins. To our knowledge, Salmonella Typhi resistant to $\beta$-lactamase by ESBL production and the genes encoding this resistance have not been described in Sri Lanka previously.

\section{Conflicts of Interest}

The authors declare that there are no conflicts of interest.

\section{Acknowledgments}

The invaluable technical assistance of Mr. Sirithilak Gamage, Chief Staff Technical Officer in the Department of Microbiology, Faculty of Medicine, University of Colombo, in molecular detection of resistance genes is gratefully acknowledged.

\section{References}

[1] R. Hassing, W. Goessens, W. van Pelt et al., "Salmonella subtypes with increased MICs for azithromycin in travelers returned to the Netherlands," Emerging Infectious Diseases, vol. 20, no. 4, pp. 705-708, 2014.

[2] S. K. Gupta, F. Medalla, M. W. Omondi et al., "Laboratorybased surveillance of paratyphoid fever in the United States: travel and antimicrobial resistance," Clinical Infectious Diseases, vol. 46, no. 11, pp. 1656-1663, 2008.

[3] C. M. Parry and E. J. Threlfall, "Antimicrobial resistance in typhoidal and nontyphoidal salmonellae," Current Opinion in Infectious Diseases, vol. 21, no. 5, pp. 531-538, 2008.

[4] R. L. Ochiai, C. J. Acosta, M. C. Danovaro-Holliday et al., "A study of typhoid fever in five Asian countries: disease burden and implications for control," Bulletin of the World Health Organization, vol. 86, no. 4, pp. 260-268, 2008.

[5] M. F. Lynch, E. M. Blanton, S. Bulens et al., "Typhoid fever in the United States, 1999-2006," JAMA, vol. 302, no. 8, pp. 859-865, 2009.

[6] Y. Pfeifer, J. Matten, and W. Rabsch, "Salmonella enterica serovar Typhi with CTX-M $\beta$-Lactamase, Germany,"
Emerging Infectious Diseases, vol. 15, no. 9, pp. 1533-1535, 2009.

[7] Clinical and Laboratory Standards Institute, Performance Standards for Antimicrobial Susceptibility Testing; Twenty Second Informational Supplement, CLSI document 100-S22, Clinical and Laboratory Standards Institute, Wayne, PA, USA, 2012.

[8] J. Kaur, S. Chopra, Sheevani, and G. Mahajan, "Modified double disc synergy test to detect ESBL production in urinary isolates of Escherichia coli and Klebsiella pneumonia," Journal of Clinical and Diagnostic Research, vol. 7, no. 2, pp. 229-233, 2013.

[9] C. Dallenne, A. Da Costa, D. Decré, C. Favier, and G. Arlet, "Development of a set of multiplex PCR assays for the detection of genes encoding important $\beta$-lactamases in Enterobacteriaceae," Journal of Antimicrobial Chemotherapy, vol. 65, no. 3, pp. 490-495, 2010.

[10] H. Fang, C. Lundberg, B. Olsson-Liljequist et al., "Molecular epidemiological analysis of Escherichia coli isolates producing extended-spectrum $\beta$-lactamases for identification of nosocomial outbreaks in Stockholm, Sweden," Journal of Clinical Microbiology, vol. 42, no. 12, pp. 5917-5920, 2004.

[11] S. Charan, R. Chander, and I. Singh, "Isolated thrombocytopenia a rare presenting feature of enteric fever," International Journal of Advances in Medicine, vol. 3, pp. 438-439, 2016.

[12] S. Dutta, D. Sur, B. Manna, S. K. Bhattacharya, J. L. Deen, and J. D. Clemens, "Rollback of Salmonella enterica serotype Typhi resistance to chloramphenicol and other antimicrobials in Kolkata, India," Antimicrobial Agents and Chemotherapy, vol. 49, no. 4, pp. 1662-1663, 2005.

[13] S. Verma, S. Thakur, A. Kanga, G. Singh, and P. Gupta, "Emerging Salmonella Paratyphi A enteric fever and changing trends in antimicrobial resistance pattern of salmonella in Shimla," Indian Journal of Medical Microbiology, vol. 28, no. 1, pp. 51-53, 2010.

[14] S. S. Bhattacharya, U. Das, and B. K. Choudhury, "Occurrence \& antibiogram of Salmonella Typhi \& S. Paratyphi A isolated from Rourkela, Orissa," Indian Journal of Medical Research, vol. 133, pp. 431-433, 2011.

[15] K. Bush, "New $\beta$-lactamases in Gram-negative bacteria: diversity and impact on the selection of antimicrobial therapy," Clinical Infectious Diseases, vol. 32, no. 7, pp. 1085-1089, 2001.

[16] V. Gupta, “An update on newer $\beta$-lactamases," Indian Journal of Medical Research, vol. 126, no. 5, pp. 417-427, 2007.

[17] V. O. Rotimi, W. Jamal, T. Pal, A. Sovenned, and M. J. Albert, "Emergence of CTX-M-15 type extended-spectrum $\beta$-lactamaseproducing Salmonella spp. in Kuwait and the United Arab Emirates," Journal of Medical Microbiology, vol. 57, no. 7, pp. 881-886, 2008.

[18] M. L. Salverda, J. A. De Visser, and M. Barlow, "Natural evolution of TEM-1 b-lactamase: experimental reconstruction and clinical relevance," FEMS Microbiology Reviews, vol. 34, no. 6, pp. 1015-1036, 2010.

[19] N. Al Naiemi, B. Zwart, M. Rijnsburger et al., "Extendedspectrum- $\beta$-lactamase production in a Salmonella enterica serotype Typhi strain from the Philippines," Journal of Clinical Microbiology, vol. 46, no. 8, pp. 2794-2795, 2008.

[20] C. M. Parry, T. T. Hien, G. Dougan, N. J. White, and J. J. Farrar, "Typhoid fever," New England Journal of Medicine, vol. 347, no. 22, pp. 1770-1782, 2002.

[21] D. Ahmed, A. Hoque, R. Mazumder, K. Nahar, N. Islam, and S. A. Gazi, "Salmonella enterica serovar Typhi strain 
producing extended-spectrum $\beta$-lactamases in Dhaka, Bangladesh," Journal of Medical Microbiology, vol. 61, no. 7, pp. 1032-1033, 2012.

[22] E. Sathishkumar, E. M. Muthu, and R. Srivani, "Detection of TEM-, SHV- and CTX-M-type $\beta$-lactamase production among clinical isolates of Salmonella species," Journal of Medical Microbiology, vol. 63, no. 7, pp. 962-967, 2014. 


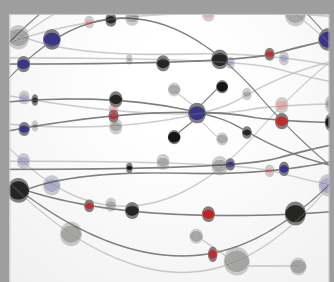

The Scientific World Journal
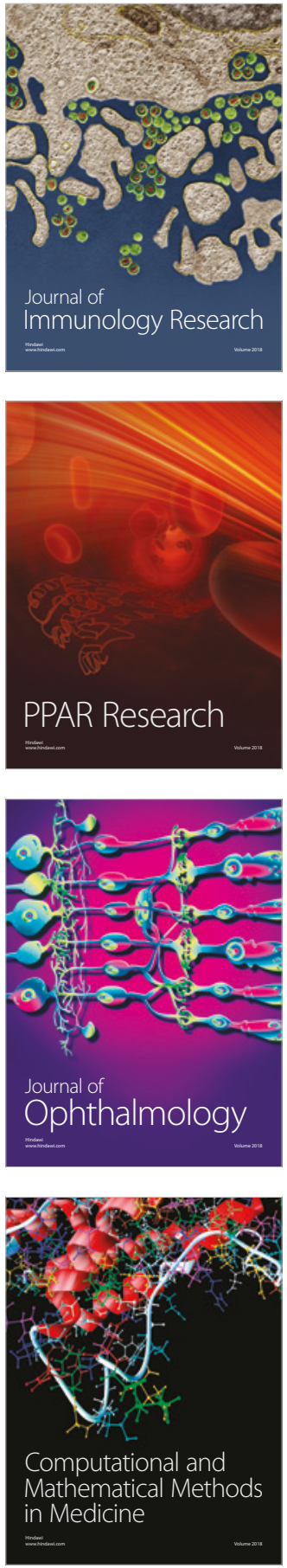

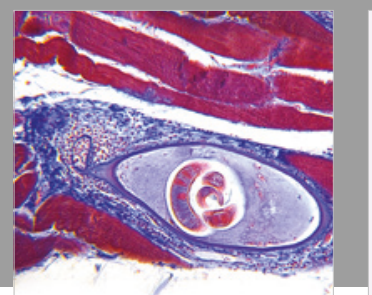

Gastroenterology Research and Practice

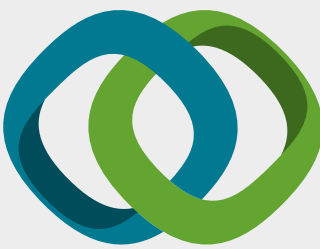

\section{Hindawi}

Submit your manuscripts at

www.hindawi.com
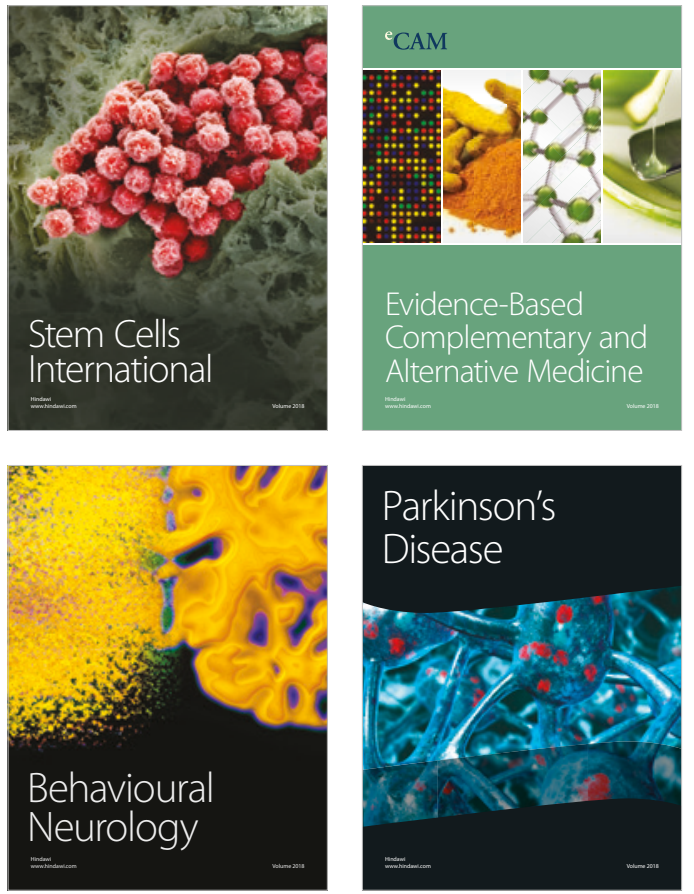

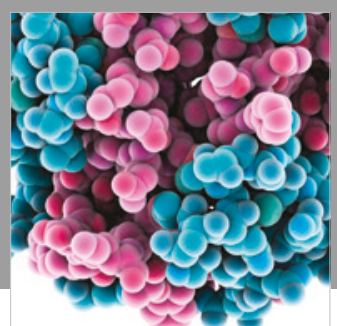

ournal of

Diabetes Research

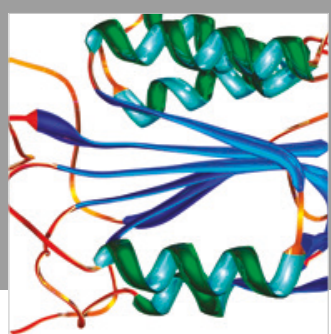

Disease Markers
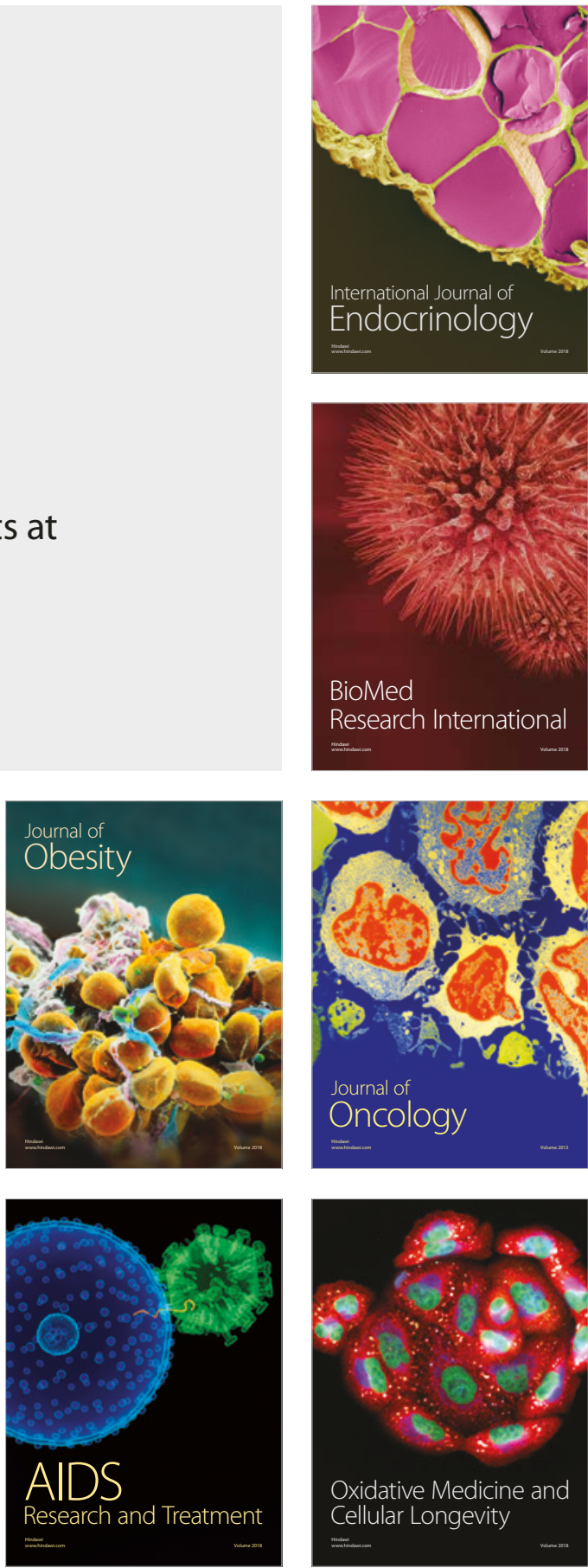